home. In the case of infectious disease there must be notification, and, nolens volens, the patient is promptly carried off to a special hospital, and though it cannot be suggested that private cases of incipient insanity should be notified, it does not seem undesirable that if a patient is in a state fraught with danger to his mental integrity ho should be denied proper treatment because of a sentimental objection to his being safeguarded! There are, in fact, cases where the measures which are freely allowed in infectious disease should be extended to mental conditions when these assume symptoms of a force dangerous to the patient or the community, and it is open to doubt if mental hospitals can be successfully carried on without some means of detaining the patient if he refuses to stay, for it is notorious that the voluntary boarder system breaks down in the very cases where one desires most to try it. The patient simply will not sign the request for admission, though knowing that he can voluntarily leave at a few hours' notice.

The proper treatment of insanity is daily becoming more complicated and individual, and, moreover, it is very expensive. I doubt if, except for the wealthy who can afford to have the aid of special advice and of any known form of treatment, it can be carried on successfully in the small private homes to which Dr. H. Rayner, in his letter to you of Feb. 7th, so properly objects. The question is full of difficulties. If-as seems to be now heldthere is a demand for hospitals for the treatment of incipient insanity where no certification and no inspection is required, by all means let the demand be met, because it may turn out that we have been unnecessarily cautious, and that certification and registration are mere bogies to which we have accorded undue reverence, but $I$ doubt if the public will be really satisfied unless there is some guarantee that the Lunacy Commissioners sanction all that is done in them. People generally have no idea of the numberless ways in which certificates and the supervision of the Commissioners protect the patients, and how they ensure that no new treatment nor anything out of the common shall be attempted before the consent of the friends is obtained.

Once certificates and supervision are abolished there is no limit to the machinations of unscrupulous persons, and many people who are now going about freely owe more than they think to the fact of the safeguard of certificates, as but for them many would certainly find themselves in captivity. I know of such cases. I should like to see the French plan of "conseil de famille" intro. duced into this country-an arrangement by which the members of a family meet in conclave, discuss the pros and cons of the case, and then act in concert. It would prevent much bickering and misunderstanding.

Brain disease when it constitutes insanity is a terrible thing for a family, and all must sympathise with any proposal which shall relieve the patient and friends from the fear of its being known. Therefore it is fitting that if the certificate does stand in the way of early treatment-a statement which is, I think, much exaggerated - the trial of a method by which free and unimpeded treatment may be obtained should be seriously contemplated. In the meantime is it altogether wise to join the chorus of those who keep on reiterating the words "slur and stigma" in connexion with certification? Surely, knowing the security afforded by these safeguards, we should use every endeavour to reassure the public and to make them see that certificates are but the legal expressions of a condition which already exists, and that it is not the certificates which make the insanity, whilst the difficulties and the dangers in the making of them are all in favour of delay in their emplorment except when other means have failed to cule or safeguard the patient.

We want the public to understand that re are quite ready to make trial of the new experiment, but perhaps under certain conditions, some of us think, such as notification and some degree of supervision, questions upon which the opinions of the Commissioners in Lunacy ought to have the greatest weight. I. am, Sir, yours faithfully,

Weymouth-street, W., March 2nd, 1914. T. Claye SHAW.

\section{A COMPARISON OF THE ACTIONS OF CHLOROFORM AND ETHER ON BLOOD PRESSURE. \\ To the Editor of THE LANCET.}

SIR,-A paper by Dr. H. P. Fairlie, anæesthetist to the Royal and Western Infirmaries, Glasgow, appeared in THE LANCET of Feb. 28th, the last paragraph of which reads as follows: "Based on those observations I think that ether is the anæs. thetic of choice for short operations or for those operations where little shock is anticipated, while chloroform is better for prolonged operations and for those where considerable shock is anticipated."

I am tempted to reply to his paper as it appears to me that he arrives at certain conclusious based on those observations which in the light of present knowledge are most certainly erroneous. He has fallen into the common error that low blood pressure causes shock and is synonymous with it. He accepts Crile's theory of-shock, "that it is a condition resulting from a fall in general blood pressure due to exhaustion of the vaso-motor centres." - This theory has been proved to be un tenable by numerous observers. Seelig and Lyon have shown that stimulation of the central end of the cut vagus causes a rise of blood pressure, and that the rise occurs even when the animals are deeply shocked, showing that the vaso-motor centre is still perfectly active.

Numerous other observers, approaching the subject from different points of view, have shown that the vaso-motor centres, far from being easily exhausted in shock, do their duty practically to the end. In this country Malcolm has written profusely on the subject, and many of his ideas on blood pressure and shock are generally accepted. The Malcolm versus Mummery controversy is still green in the minds of those who are interested in the subject.

I quite agree with Dr. Fairlie that a sudden fall of blood pressure during an operation may well mean shock and may be due to the anæsthetic, but I fail to see how he can attribute a fall of blood pressure, in which'there is practically no change in the pulse-rate nine hours after the operation, to the ether which he administered during the opera. tion. There may be other explanations (see Chart 4). He gives us no clinical data as to the condition of the patient apart from the blood pressure-one man with a blood pressure of 100 may be in extremis, while another may be little affected; this shoms the error of considering blood pressure as synonymous with shock. Judging from the Charts 3 and 4 in Dr. Fairlie's paper I would not expect that 
either of the cases would be classified as operations which had involved a severe degree of shock.

Referring to the post-operative condition he writes as follows: "At a time when it is of vital importance that patients should make use of all their resources, after chloroform anæsthesia they are better able to do so than after ether." If Dr. Fairlie is correct it means that almost every surgical clinic in the world is wrong, and that practical experience has gone for nothing. Chloroform has had its day-open ether has ousted it completely. Chloroform is much the more toxic drug; it is more difficult to administer safely and is much more conducive to shock. All experience goes to support this statement. Chloroform should never be used alone, and never as the terminal anæsthetic. Whenever I see it administered I always think what a foolhardy procedure it is - a highly dangerous drug is being administered in quite unknown doses. I can hardly conceive a condition, at any rate in hospital practice, in which there is any excuse for administering it. In a few clinics chloroform is still used in special cases as an introduction to open ether, but $I$ am doubtful if it is advisable in many of those cases.

Scotland, the home of chloroform, stuck to its own far longer than was justifiable. I am glad to see it banished or nearly so. We have much to learn from the American surgeons on the subject of anæsthesia. They are ahead of us, and the further west you go the further on they are. Just as open ether has displaced chloroform, so it in its turn is being displaced by nitrous oxide and oxygen, a combination which is suitable in a large percentage of cases. Undoubtedly it has disadvantages. It requires special apparatus and special knowledge, but its adrocates can say of it that it is the safest general anæsthetic known, being practically nontoxic.

Gas and oxygen when combined with local anæsthetics and sedatives according to Crile's anociassociation method ${ }^{1}$ is claimed to have solved the problem of shock. The technique is complicated, requiring time and trouble, but I do not think that there is any doubt that the results justify the proud claims that have been made for this method. It is certainly a great advance, and I would suggest that Dr. Fairlie should compare his charts with those of Bloodgood, published in the Annals of Surgery, December, 1913, in which anoci-association method has been carried out.

In the light of present knowledge it is hardly fair to subject patients whose ability to stand an operation of very great magnitude is highly problematical to a more dangerous anæsthetic than gas and oxygen properly administered; and anæsthetists highly trained in the use of gas and oxygen are much needed for major operations. As to Dr. Fairlie's recommendation to start with ether and continue with chloroform, surely in spite of all theories to the contrary this is exceedingly bad advice. I have had more frights when seeing this method carried out than any other. Your anæsthetist, unfortunately very frequently quite inexperienced, is requested to administer ether by the open method. Owing to his faulty methods he fails to keep the patient under sufficiently, and on being remonstrated with pours in a liberal supply of chloroform; the patient, who is breathing deeply under the influence of the ether, rapidly gulps down a large dose of chloroform, a highly toxic drug, and the result is just what one would expect, the patient's respiration or circulation fails. I fully realise that the above sequence of events is not so likely to occur in the hands of an expert.

I may say I have substituted my chloroform bottle in my midwifery bag for a larger one which contains ether, and I have every reason to be satisfied with the change. All honour to the discoverer of chloroform, but his discovery has had its day, and I hardly think that Dr. Fairlie will resurrect it by his blood pressure observations.

I am, Sir, yours faithfully,

G. MoCalL Smith, M.B., Ch.B. Edin., Perth, Feb. 28th, 1914. F.R.C.S.Edin.

\section{PAROXYSMAL TACHYCARDIA IN A CHILD.} To the Editor of THE LANCET.

SIR,-In your issue of March 7 th is recorded a case of this kind which was shown at the Royal Society of Medicine. Dr. G.A. Sutherland, I see, asked what was the prognosis. Little, I think, is known on this point, and therefore it may interest your readers to know that a patient whom I saw when she was 11 years old, and described in the Clinical Society's Transactions, vol. xxx., in 1897, is now a stewardess on an Atlantic liner. I believe Dr. Sutherland, who was my colleague at the Paddington Green Children's Hospital, saw her with me at the time. I am, Sir, yours faithfully,

Wimpole-street, W., March 9th, 1914. W. P. Herringham.

\section{GANGRENE OF THE INTESTINE.}

\section{To the Editor of THE LANCET.}

SIR,-The case of acute suppurative appendicitis complicated by gangrene of the ileum published by Mr. Basil Hughes in THE LANCET of March 7th is of interest from more than one point of view.

In the first place, the condition of anæmic gangrene which obtained is one of great rarity when it involves the intestine. In a recent monograph $^{1}$ I was able to collect 9 cases only of anæmic infarction of the intestine; of these cases 6 and possibly 2 more involved the ileum.

With regard to the pathology of anæmic infarction of the intestine one may say that no entirely satisfactory hypothesis has been brought forward to explain all the facts, though it appears that a gradual cutting off (e.g., by endarteritis, arteriosclerosis, or atheroma of the mesenteric branches) of the arterial circulation is an important factor. Embolism alone in practically all cases leads to hæmorrhagic lesions ranging from a few petechiæ on the one hand to infarction on the other.

A second interesting feature of Mr. Hughes's case is the history. There appears to have been a period of relative freedom from symptoms after the acute onset. This "latent" period was followed by further acute manifestations. The course of erents therefore was more in accordance with what one might expect in a case of hremorrhagic infarction due to venous thrombosis arising from an inflamed appendix than in one of anremic gangrene of the intestine. - I am, Sir, yours faithfully,

Leslie B. C. Trotter, M.A., B.C. Cantab. Ledbury, Herefordshire, March 9th, 1914. 